\title{
Family Medicine Research on Health Equity, Addiction, and Eating Breakfast-Just for Starters
}

\author{
Dean A. Seebusen, MD, MPH, Marjorie A. Bowman, MD, MPA, and \\ Christy J. W. Ledford, PhD
}

As usual, this issue of the journal delivers reports on a broad range of topics that can inform clinical practice. Several articles address equity, or the lack thereof, in health care. This includes research on the social determinants of health and how family medicine can contribute to redressing inequity. Another set of articles report on the ongoing wave of substance abuse. Additional training in addiction medicine for family physicians is 1 strategy for the United States to address this crisis. One of the most intriguing articles looks at the relationship between eating breakfast, amount of dietary fiber intake, and mortality. Several articles discuss ongoing changes or changes to family medicine on the horizon. Readers will find some well-written clinical reviews and an in-depth review of international practice-based research networks. Lastly, 2 great reads will remind readers how it feels to practice family medicine. ( $\mathrm{J}$ Am Board Fam Med 2021;34:675-677.)

\section{News of the Day}

Your mother may have told you that breakfast was the most important meal of the day. She probably did not daily remind you how much fiber to eat each morning. In a study with important patient education implications, King and Xiang ${ }^{1}$ combined long-term follow-up mortality data with data from the National Health and Nutrition Examination Survey to show that mother may have been onto something. This study should change the way you counsel your patients on nutrition.

That face masks decrease the spread of COVID19 seems to be settled science at this point. ${ }^{2}$ But we're still seeking answers for patient-centered concerns such as the physiologic effects of wearing face masks, especially during periods of exertion. A group of Israeli researchers ${ }^{3}$ help answer that question.

\section{Evidence for Clinical Practices in Response to Social Determinants of Health (SDoH)} Continuing to build the evidence base for the effects of SDoH, Bonnell et al. ${ }^{4}$ find SDoH correlate with functional capacity among patients with chronic conditions. In recent years, research has explored the feasibility and effectiveness of screening and intervening to address SDoH. Clinician buy-in is clearly key to successfully implementing screening and referral programs. ${ }^{5}$ Further,

Conflict of interest: The authors are editors of the $7 A B F M$. community organizations can contribute to addressing SDoH that affect chronic disease outcomes. Hanh et $\mathrm{al}^{6}$ argue that health care systems should partner with these organizations to address social determinants and, ultimately, improve the health of communities. Heintzman and Marino ${ }^{7}$ take a further step back to offer a special communication that elaborates how primary care research can help clarify health inequity in the United States. Their scoping review defines what is known on this topic and where more research is needed.

Point-of-care ultrasound (POCUS) has been hailed as a technology that could become the 21st century equivalent of the stethoscope. Can family physicians foster health equity through the wider use of POCUS, as argued by Dr. Tanael? ${ }^{8}$ And, are family physicians adopting POCUS, a tool whose potential uses continues to grow? ${ }^{9}$ Shen-Wagner ${ }^{10}$ comments on Niblock et al. ${ }^{9}$ and the status of POCUS, emphasizing the need to create more training for family physicians, as has been done in other specialties.

\section{Reports Related to Drugs of Abuse- Opioids, Heroin, Cannabinoids}

As the opioid overdose crisis continues, researchers ask questions about opioid misuse and prescribing. In this issue, a national survey of health care providers explored how opioid prescribing education is associated with opioid prescribing patterns. ${ }^{11}$ Although most health care providers had received 
education about opioid prescribing in the prior 12 months, significant knowledge gaps remained. In addition to misuse, 1 of the dangers of prescribing opioids is the development of addiction: some patients subsequently turn to street opioids, including heroin. Suzuki and Reddy ${ }^{12}$ educate us on a specific danger from contaminated heroin.

Increasing incidence of cannabinoid hyperemesis syndrome may be connected to the increasing number of US states that have legalized recreational marijuana. Athletes are 1 population who are less likely to openly disclose marijuana use. Brady and $\mathrm{Kim}^{13}$ present this case of unexpected athlete marijuana use as a starting point for a comprehensive review of the literature on a condition we will likely see more of in the future.

Given the number of patients with substance use disorder, it is unfortunate that only a small percentage of family physicians are also board certified in addiction medicine. Tong et al.'s ${ }^{14}$ report on current dually certified physicians shows an impressive scope of practice, often for the most vulnerable patients. The authors suggest some ways this highly trained subset of family physicians could be strategically utilized.

\section{Clinical Medicine}

A quartet of articles explore some interesting ways that clinical medicine is, or may soon be, changing. (1) A report from the Netherlands ${ }^{15}$ describes a bold experiment in fundamentally changing documentation in the electronic health record by making patients' stories a robust part of the medical record. The authors further discuss how this innovation influenced patient encounters during the COVID-19 pandemic. (2) We all want patients to be educated about their health needs, and health information is available through a variety of sources and media. For Black men seeking information about prostate cancer, 1 option is YouTube. ${ }^{16}$ Understanding the accuracy or inaccuracy of that advice is important in this digital age. (3) It is likely just a matter of time before genetic screening is conducted at the population level, and family physicians are well positioned to lead that initiative. A report from David et al. ${ }^{17}$ gives us an early preview of such a screening program. (4) Nogues et al. ${ }^{18}$ review human papillomavirus positive head and neck cancers.

Musculoskeletal complaints are among the most common problems seen in family medicine. Bodenhei- mer et al. ${ }^{19}$ describe 1 health system's successful approach to integrating physical therapists into primary care. The authors offer a blueprint for use by other systems wishing to expand interprofessional care in this high demand area. Atwell et al. ${ }^{20}$ provide a very detailed clinical review of hypermobility spectrum disorder.

\section{Mental Health}

An in-depth analysis of Medical Expenditure Panel Surveys data shows that the number of Americans using psychiatric medications has increased over the last 2 decades. The increase has not been equal by gender and age. Wide variation exists among medication categories, although the variation has decreased over time. This report ${ }^{21}$ presents rich data and raises stimulating questions about what is driving these changes. Potential interpretations of the findings will be diverse and potentially contradictory.

The American Academy of Family Physicians has developed an Adult ADHD Toolkit to help family physicians provide quality care for the increasing number of adults with a diagnosis of ADHD. Loskutova et al. ${ }^{22}$ evaluated how providers felt about the toolkit and report overall positive results.

\section{Family Practice-Based Research}

Rural practices, especially independent rural practices, are less likely to have resources available to conduct regular quality improvement. What happens when quality improvement resources, such as expert facilitation, are made available to such practices? Fagnan et al. $^{23}$ report findings from the Healthy Hearts Northwest Study.

Dania et al. ${ }^{24}$ present a review of Practice Based Research Network (PBRN) activities from around the world, covering PBRN literature from 15 countries over 50 years.

\section{The Nature and Nurture of Family Medicine}

The issue wraps up with some must-reads about the nature of family medicine. Dr. Hill ${ }^{25}$ provides a timely reminder of the centrality of interpersonal relationships-the heart and soul of family medicine. She describes this as "slow medicine." Dr. Pine $^{26}$ clearly knew something about practicing slow medicine. You will want to read about the impact his 34-year career had on his patients and his patients' impact on him. 
To see this article online, please go to: http://jabfm.org/content/ 34/4/675.full.

\section{References}

1. King DE, Xiang J. A relationship between mortality and eating breakfast and fiber. J Am Board Fam Med 2021;34:678-687.

2. Czypionka T, Greenhalgh T, Bassler D, Bryant MB. Masks and face coverings for the lay public: a narrative update. Ann Intern Med 2021;174:511-20.

3. Bar-On O, Gendler Y, Stafler P, et al. Effects of wearing facemasks during brisk walks: a COVID-19 dilemma. J Am Board Fam Med 2021;34:798-801.

4. Bonnell LN, Crocker AM, Kemp K, Littenberg B. The relationship between social determinants of health and functional capacity in adult primary care patients with multiple chronic conditions. J Am Board Fam Med 2021;34:688-697.

5. Quiñones-Rivera A, Wing HE, Barr-Walker J, Yee M, Harrison JM, Gottlieb LM. Provider impacts of socioeconomic risk screening and referral programs: a scoping review. J Am Board Fam Med 2021;34:820-831.

6. Nguyen KH, Fields J, Cemballi AG, et al. The role of community-based organizations in improving chronic care for safety-net populations. J Am Board Fam Med 2021;34:698-708.

7. Heintzman J, Marino M. The importance of primary care research in understanding health inequities in the United States. J Am Board Fam Med 2021;34:849-852.

8. Tanael M. Use of point-of-care ultrasonography in primary care to redress health inequities. J Am Board Fam Med 2021;34:583-855.

9. Niblock F, Byun H, Jabbarpour Y. Point-of-care ultrasound use by primary care physicians. J Am Board Fam Med 2021;34:859-860.

10. Shen-Wagner J. Family medicine billing for pointof-care ultrasound (POCUS). J Am Board Fam Med 2021;34:856-858.

11. Price SM, O'Donoghue AC, Rizzo L, Sapru S, Aikin KJ. Opioid education and prescribing practices. J Am Board Fam Med 2021;34:802-807.

12. Suzuki HT, Reddy H. Cranial nerve palsy secondary to botulism after black tar heroin use. J Am Board Fam Med 2021;34:808-810.

13. Fleshman B, Kaiser K. Cannabinoid hyperemesis syndrome in an athlete. J Am Board Fam Med 2021;34:811-813.
14. Tong ST, Morgan ZJ, Bazemore AW, Eden AR, Fitzgerald RM, Peterson LE. Practice patterns of family physicians with and without addiction medicine board certification. J Am Board Fam Med 2021;34:814-819.

15. Luijks H, van Boven K, olde Hartman T, Uijen A, van Weel C, Schers H. Purposeful incorporation of patient narratives in the medical record in the Netherlands. J Am Board Fam Med 2021;34:709_ 723.

16. Shungu N, Haley SP, Berini CR, Foster D, Diaz VA. Quality of YouTube videos on prostate cancer screening for Black men. J Am Board Fam Med 2021;34:724-731.

17. David SP, Dunnenberger H, Ali R, et al. Implementing primary care mediated population genetic screening within an integrated health system. J Am Board Fam Med 2021;34:861-865.

18. Nogues JC, Fassas S, Mulcahy C, Zapanta PE. Human papillomavirus-associated head and neck cancer. J Am Board Fam Med 2021;34:832-837.

19. Bodenheimer T, Kucksdorf J, Torn A, Jerzak J. Integrating physical therapists into primary care within a large health care system. J Am Board Fam Med 2021;34:866-870.

20. Atwell K, Michael W, Dubey J, et al. Diagnosis and management of hypermobility spectrum disorders in primary care. J Am Board Fam Med 2021;34:838-848.

21. Johansen ME. Psychiatric medication users by age and sex in the United States, 1999-2018. J Am Board Fam Med 2021;34:732-740.

22. Loskutova NY, Lutgen CB, Callen EF, Filippi MK, Robertson EA. Evaluating a web-based adult ADHD toolkit for primary care clinicians. J Am Board Fam Med 2021;34:741-752.

23. Fagnan LJ, Ramsey K, Dickinson C, Kline T, Parchman ML. Place matters: closing the gap on rural primary care quality improvement capacitythe Healthy Hearts Northwest Study. J Am Board Fam Med 2021;34:753-761.

24. Dania A, Nagykaldi Z, Haaranen A, et al. A review of 50-years of international literature on the internal environment of building practice-based research networks (PBRNs). J Am Board Fam Med 2021;34:762-797.

25. Hill E. Slow medicine. J Am Board Fam Med 2021;34:871-873.

26. Pine D. Retirement tea. J Am Board Fam Med 2021;34:874-877. 